\title{
Leisure Constraints for Adolescents in Cape Town, South Africa: A Qualitative Study
}

Lori-Ann Palen $^{a}$, Megan E. Patrick b , Sarah L. Gleeson c , Linda L. Caldwell d , Edward A. Smith ${ }^{\mathrm{e}}$, Lisa Wegner ${ }^{\mathrm{f}}$ \& Alan J. Flisher $\mathrm{g} \mathrm{h}$

a Risk Behavior and Family Research Program, RTI International, Research Triangle Park, NC, USA

b Institute for Social Research, University of Michigan, Ann Arbor, MI, USA

c Department of Recreation, Park and Tourism Management, The Pennsylvania State University, University Park, PA, USA

d Department of Recreation, Park and Tourism Management, Department of Human Development and Family Studies, The Pennsylvania State University, University Park, PA, USA

e Prevention Research Center for the Promotion of Human Development, Department of Human Development and Family Studies, The Pennsylvania State University, University Park, PA, USA

f Occupational Therapy Department, University of the Western Cape, Bellville, South Africa

$\mathrm{g}$ Division of Child and Adolescent Psychiatry, University of Cape Town, Cape Town, South Africa

$\mathrm{h}$ Research Centre for Health Promotion, University of Bergen, Bergen, Norway Version of record first published: 30 Sep 2010.

This study identified leisure constraints, constraints negotiation strategies, and their relative frequencies among 114 high school students from one under-resourced area of South Africa. Through focus group discussions, participants identified intrapersonal, interpersonal, structural, and sociocultural constraints to leisure, suggesting some de- gree of universality in this previously documented typology. Intrapersonal constraints were mentioned most often. Whereas participants readily identified ways to overcome interpersonal and structural constraints, strategies for overcoming intrapersonal and sociocultural constraints were not mentioned frequently, suggesting a potential need to help adolescents identify and employ these types of strategies.

Keywords adolescents, leisure constraints, leisure constraint negotiation, South Africa

\section{Introduction}

Leisure participation has been linked to a number of positive 
developmental experiences in adolescence, including opportunities for identity work (Dworkin, Larson, \& Hansen, 2003; Kleiber, 1999), skill development (Hansen, Larson, \& Dworkin, 2003), relation- ship building (Eccles, Barber, Stone, \& Hunt, 2003), movement toward independent/adult status (Iso-Ahola, 1980; Kelly, 1987), and positive emotional experiences (Kleiber, Lar- son, \& Csikszentmihalyi, 1986). Alternatively, a lack of leisure activity involvement has been linked to elevated levels of internalizing and externalizing behavior and lower levels of academic performance and skills, such as problem-solving (Bartko \& Eccles, 2003). In short, a lack of participation in positive leisure, either by choice or because of external forces, can hinder healthy adolescent development (Caldwell \& Baldwin, 2005). It is important, therefore, to understand the potential reasons adolescents are unable to participate in leisure activities, as well as the resources they may have to circumvent these barriers.

This study aims to describe leisure constraints among adolescents from an under- resourced area of South Africa, a group in which these constraints have yet to be examined. We document the nature and prevalence of various types of constraints as well as the strategies that adolescents have for negotiating them. It is our intent to highlight areas of need and opportunity so that individuals interested in promoting adolescent well-being (e.g., parents, educators, policy makers, adolescents themselves) might undertake efforts to reduce constraints, build negotiation skills, and increase subsequent participation in leisure activities.

\section{Constraints to Leisure Participation}

Leisure constraints are "internal (intrapersonal) psychological states, attributes, and characteristics, and external (interpersonal and situational) circumstances which are experienced as individual behavioral "restraining forces"' (Crawford \& Godbey, 1987, p. 122). Early research focused on reduced/prohibited leisure participation as the main outcome of leisure constraints; however, more recent studies argue that constrained individuals might participate in leisure, but they may enjoy their participation less and reap fewer benefits from it (see Samdahl, 2005; Samdahl \& Jekubovich, 1997). 
proposed by Crawford and Godbey (1987). Their hierarchical model includes intrapersonal, interpersonal, and structural constraints. Intrapersonal constraints are personal states or characteristics that limit one's preference for an activity. Documented intrapersonal constraints include insufficient skills; health/fitness limitations; height; weight; mood; laziness; boredom; body- consciousness; concerns about one's appearance; and lack of interest, self-esteem, energy, discipline, or motivation (Allison, Dwyer, Goldenberg, Rein, Yoshida, \& Boutilier, 2005; Allison, Dwyer, \& Makin, 1999; Gyurcsik, Spink, Bray, Chad, \& Kwan, 2006; Hultsman, 1992; Jackson \& Rucks, 1995; James, 2000; Liechty, Freeman, \& Zabriskie, 2006; Samdahl \&Jekubovich,1997).

Interpersonal constraints result from interactions between individuals (Crawford \& Godbey, 1987). Like intrapersonal constraints, interpersonal constraints can limit one's preference for a given activity; they can also block participation in activities for which an individual has a preference. Interpersonal constraints include family responsibilities (Allison et al., 1999; Samdahl \& Jekubovich, 1997), lack of suitable/available leisure partners (Gordon-Larsen, Griffiths, Bentley, Ward, Kelsey, Shields, \& Ammerman, 2004; Jackson \& Rucks, 1995; Samdahl \& Jekubovich, 1997), lack of physically active role models (Gordon-Larsen et al., 2004), and disapproval from parents and peers (Allison et al., 2005; Jackson \& Rucks, 1995). A study of early adolescents found that parents and activity leaders were among the strongest interpersonal leisure constraints (Hultsman, 1993).

Structural constraints prevent participation among individuals who have a preference for a given activity (Crawford \& Godbey, 1987). Empirical examples include cost, avail- ability of facilities/equipment/teams, location and transportation, and the times at which an activity is offered (Allison et al., 2005; Gordon Larsen et al., 2004; Gyurcsik et al., 2006; Hultsman, 1992; Jackson \& Rucks, 1995; Samdahl \& Jekubovich, 1997).

Recently, there have been calls for research to consider sociocultural leisure constraints (Caldwell \& Baldwin, 2005). Although this type of constraint receives minimal attention in Crawford and Godbey's hierarchy, its inclusion is justified by ecological theory, which posits that "economic, social, educational, legal, and political systems" 
shape individual behavior and interpersonal interaction (Bronfenbrenner, 1977, p. 515), in part through the values they engender. Cultural values shape leisure opportunities, as well as demands on time and energy that could constrain leisure (Chick \& Dong, 2003; Silbereisen, 2003). These values may differ depending on gender (e.g., Verma \& Sharma, 2003) or within subcultures as defined by race/ethnicity (e.g., Philipp, 1995), religion (e.g., Stodolska \& Livengood, 2006), age, or other factors.

\section{Overcoming Leisure Constraints}

Jackson and colleagues' negotiation proposition holds that "participation is dependent not on the absence of constraints (although this may be true for some people) but on negotiation through them" (Jackson, Crawford, \& Godbey, 1993, p. 4). This proposition is supported by empirical evidence that negotiation mediates the association between leisure constraints and participation (Hubbard \& Mannell, 2001). Documented leisure constraint negotiation strategies include acquiring leisure skills, improving one's finances, participating in physical therapy, modifying time use and personal relationships, and changing one's preferences (Hubbard \& Mannell, 2001; Jackson \& Rucks, 1995; Samdahl \& Jekubovich, 1997).

Identifying constraints and then either reducing them or providing resources for over-coming them seems to be a viable strategy for increasing leisure participation and associated developmental benefits. Unfortunately, the existing literature tends to take a disjointed approach to leisure constraints and negotiation strategies; constraints and methods for over-coming them are identified in separate analyses without the explicit intent of examining the correspondence between them. Consequently, practical questions remain unanswered. Are there specific leisure constraints for which adolescents do not currently have negotiation strategies? Are there constraints for which adolescents have multiple plausible negotiation strategies and, therefore, do not need to be targeted with interventions? Answering these questions is essential for planning efficient and effective interventions to reduce the impact of leisure constraints on leisure participation and experiences. 


\section{Leisure Constraints in South Africa}

There is ample evidence that leisure constraints vary by population group, whether defined by income, age, gender, race/ethnicity, or disability status (Scott, 2005). Therefore, to intervene within a specific population, it is crucial to have information on leisure constraints and their negotiation within that population.

Currently, little is known about constraints to leisure among South Africans. To the best of our knowledge, there is only one study that examined leisure constraints in South Africa, which specifically examined constraints to soccer participation among adult women in the Western Province (Pelak, 2005). This study showed evidence of intrapersonal, interpersonal, structural, and sociocultural constraints. For example, women experienced discrimination because of their participation in a traditionally male sport. They also encountered constraints in finances, facilities, coaches, equipment, transportation, lack of media coverage or public support, and time constraints caused by childrearing and other responsibilities. White and Colored (derived from Asian, European, and African ancestry; see discussion of apartheid below) women had better access to soccer than did Black South African women. In terms of overcoming these constraints, participants discussed mentoring younger players as one negotiation strategy.

Based on studies from other areas of the world, we might speculate on the nature of leisure constraints for South Africa adolescents. Income, for example, may serve as a structural constraint, as well as having implications for intra- and interpersonal constraints. At the time the present study was conducted, more than one third of South Africans lived on less than US\$2 per day (United Nations Development Programme, 2006), and the national unemployment rate was more than 20\% (Statistics South Africa, 2007). This economic hardship may constrain leisure involvement by limiting both time and financial resources that can be devoted to leisure (Larson \& Verma, 1999). Individuals with low income or socioeconomic status express the lowest interest in starting new activities, perceive stronger intrapersonal constraints, and experience the strongest effects of barriers, as compared with individuals in better economic situations (Raymore, Godbey, \& Crawford, 1994; Searle \& Jackson, 1985). This 
implies that leisure constraints for low-income South African adolescents may be both numerous and strong.

Most likely, South African cultural values also play a role in perceptions of leisure constraints. Unfortunately, little is known about leisure-related values in this population or how they might compare to other nations. A number of South Africans are of Southeast Asian descent (Colored and Indian population groups; see discussion of apartheid below). Because other Asian emigrants may share similar religious and cultural values, the findings from studies of these populations may inform hypotheses about subpopulations of South Africans. For example, a study of South Asian adolescents living in England found evidence for a number of culturally related constraints to sports involvement (Fleming, 1993), including feeling uncomfortable with showing one's body, lacking sports role models of one's own ethnicity, parents who valued academics and "adult-like" behavior over sports participation, and, for boys, a machismo that inhibited participation in "feminine" activities. Some constraints were explicitly linked to the Islamic faith, including having to engage in prayer throughout the day and prohibitions against activities such as dancing.

Issues of constraint in South Africa are also shaped by the legacy of apartheid. The Population Act of 1950 (and its subsequent amendments) established four population groups in South Africa: Black, White, Colored, and Indian (Ellison, de Wet, IJsselmuiden, \& Richter, 1996). These groups were "based on a variety of factors, including appearance, descent, language, and behavior" (p. 1259), and they were intended to formalize discrimination. Although apartheid policy has since been repealed, persons classified as Black, Colored, or Indian have continued to remain at a relative social and economic disadvantage (United Nations Development Programme, 2000). Hypotheses about population group differences in leisure constraints might be informed by studies of racial differences in leisure constraints in the United States (e.g., Philipp, 1995). In particular, it is possible that marginality, cultural values, and discrimination may uniquely constrain some South Africans.

\section{The Current Study}


The current study had three aims, all of which were explored using qualitative focus groups. First, we documented the perceived constraints to leisure involvement among a group of adolescents from an under-resourced area of Cape Town, South Africa. We anticipated that participants would mention intrapersonal, interpersonal, structural, and sociocultural constraints. Second, we discussed the relative frequency with which each type of constraint was mentioned. Based on previous studies (Gyurcsik et al., 2006; Raymore et al., 1994), we believed that intrapersonal constraints would be especially common. Also, given the low-income status of this population, we expected certain structural constraints (e.g., cost, transportation) to be frequently mentioned. Third, we discussed the ways adolescents reported that they do, or could, overcome these barriers. In particular, we explored whether there were certain constraints for which adolescents did not mention negotiation.

\section{Methods}

\section{Participants}

The sample for this study was drawn from the HealthWise South Africa research trial (Caldwell et al., 2004) conducted in Mitchell's Plain, a low-income township near Cape Town that was established during the apartheid era. In determining which of 25 high schools in the Mitchell's Plain area to include in this study, six were excluded because of concerns about their ability to functionally participate. Of the remaining schools, four were randomly selected to receive the HealthWise curriculum. Five schools served as comparison schools; however, data from these students were not included in the current study.

The focus group participants for the present study $(N=114)$ were selected from students at the four HealthWise intervention schools. Students in Mitchell's Plain typically speak English, Afrikaans, and/or Xhosa. However, because the primary investigators for the focus group sub-study spoke only English, students without English proficiency (estimated at $30 \%$ or less of population; see Palen, Caldwell, Smith, Gleeson, \& Patrick, 2008) were excluded. Quantitative data collected approximately two months after the focus groups were conducted (see Palen et al., 2008) show that the mean ages of all eighth and tenth grade HealthWise students were 14 and 16, respectively. Most 
participants were Colored (87\%), with the rest of the students being Black (9\%), White (3\%), or Indian or other (1\%).

\section{Participant Recruitment and Data Collection}

Focus groups were used for this study because they promote potentially synergistic discussion about topics of interest, and they are an efficient way of collecting large quantities of qualitative data (Stewart, Shamdasani, \& Rook, 2007). Potential participants were selected at random from a list of students identified by their teachers as being able to express them- selves verbally in English. The following were targeted for recruitment from each school: 10 eighth grade girls, 10 eighth grade boys, 10 tenth grade girls, and 10 tenth grade boys.

The curriculum's Youth Development Specialists visited selected students to explain the study and gauge interest. If students were interested in participating, they read an in- formation letter and completed an assent form. In addition, students were given a consent form/information letter to carry home to their parents or guardians. Students were responsible for returning the signed parental consent forms to the Youth Development Specialists. For each student who was not willing to participate, an additional student was selected at random and recruited following this procedure.

Focus group sessions were conducted separately by gender and by grade. Sessions were held in unused classroom spaces in each of the schools. The focus groups typically took place during school hours, with students being pulled out of their scheduled courses. However, one school required sessions to be scheduled after school.

Students from the population of interest have relatively high levels of school absence. Therefore, not all recruited students actually participated in a focus group session. The 15 focus groups consisted of 4-10 participants each. At one school, only two tenth grade boys arrived for their focus group; consequently, this session was cancelled.

Each focus group lasted approximately 90 minutes. The groups were moderated by two members of the U.S. research team. Each session began with a warm-up game and facilitator introductions. Students then answered questions about a variety of topics, including free- time 
activities, substance use, sexual behavior, and the HealthWise intervention. During the focus group discussions, the facilitators encouraged the expression of multiple and diverse viewpoints through the use of probes, such as "Anything that anyone would like to add?" and "Does anyone have a different answer?" Each session concluded with a time for refreshments, and each student was given a T-shirt as a token of appreciation for participating.

Focus groups were audiotaped and then transcribed verbatim by a South African transcriptionist. Members of the U.S. and South African research team then checked all transcripts for accuracy.

\section{Qualitative Measures}

At the outset of the focus group, the facilitator defined free time as "time that you're not spending in class, doing school work, or doing chores at your home" and free-time activities as "things like clubs or events, and they could take place in your school, your home, or your community" during free time. Participants were then asked to draw pictures of free-time activities that went on in their area, either things they did or other students did.

Participants were asked to share activities from their drawings. As each activity was mentioned, the facilitator asked how participants felt about the activity, and what elements they specifically liked and disliked. The responses about dislikes often reflected constraints to either initiating or continuing participation.

Later in the focus group discussion, the facilitator asked specifically about "things that get in the way" of doing activities that the adolescents listed. Following the generation of a list of obstacles, the facilitator asked, "What are some ways that you overcome or could overcome these obstacles?" The facilitator also asked whether all adolescents were able to participate in the activities that had been listed, or whether any types of adolescents were excluded from participation.

\section{Data Analysis}


Three of the authors coded the focus group transcripts for information relevant to the current study. An initial coding scheme was developed based on theory and the authors' impressions from having conducted the groups. To achieve reliability (see Creswell \& Plano Clark, 2007), each of the coders applied the scheme to each transcript independently. Then, the three discussed the transcripts. Any discrepancies were resolved by consensus. Consistent with the constant comparative method for establishing validity in qualitative research, the coding scheme was modified as needed to accommodate unanticipated information (Silverman, 2005).

Transcripts and their corresponding codes were then entered into ATLAS.ti software. Quotation lists for each code were then reviewed by the coders to verify that the codes were applied consistently and correctly across transcripts. The final coding list (including example quotes) was then reviewed by a fourth author who did not participate in the coding process but was highly familiar with both the population and constructs of interest. This type of external audit is an accepted procedure for establishing the validity of qualitative results (Creswell \& Miller, 2000).

Two types of information were coded in the responses to the focus group questions listed above: leisure constraints and methods for overcoming them. Leisure constraints were coded as intrapersonal, interpersonal, structural, sociocultural, or "other" (for those constraints that did not fit neatly under an existing type). To increase the level of detail in analysis, sub codes were used under each of these broad categories (Table 1). Also, when multiple constructs were discussed within the same passage, multiple codes were applied. Participants' comments about overcoming constraints were also assigned to the category corresponding with the type of constraint being overcome.

\section{Results}

\section{Leisure Constraints}

Intrapersonal constraints. Intrapersonal constraints were mentioned in all 15 focus groups, and, as compared with the other 
types of constraints, they were mentioned the most times across groups (Table 1). The most frequently mentioned intrapersonal constraint was a lack of interest in or dislike for an activity, and this constraint manifested in a number of diverse ways. Participants discussed disliking certain activities in general, as well as specific aspects of activities. In particular, participants discussed a number of experiences that they disliked in sports, including physical exertion, getting dirty, losing, and having to follow certain rules. One example among eighth grade girls came up in the context of netball, a sport that is similar to basketball and typically played by girls: 
TABLE 1 Constraints Discussed in Focus Groups

\begin{tabular}{|c|c|c|c|}
\hline Constraint type & $\begin{array}{l}\text { Number of groups } \\
\text { mentioning } \\
\text { constraint }\end{array}$ & $\begin{array}{l}\text { Total mentions of } \\
\text { constraint across } \\
\text { groups }\end{array}$ & $\begin{array}{l}\text { Total mentions of } \\
\text { ways to overcome } \\
\text { constraint }\end{array}$ \\
\hline Intrapersonal (total) & 15 & 180 & 6 \\
\hline Lack of interest/dislike (total) & 15 & 119 & 0 \\
\hline Competing interests & 10 & 22 & 0 \\
\hline Dislike of losing & 9 & 17 & 0 \\
\hline Boring activity & 8 & 9 & 0 \\
\hline Dislike of antisocial & 7 & 9 & 0 \\
\hline Lack of skill/ability & 13 & 22 & 0 \\
\hline $\begin{array}{l}\text { Lack of ability due to health } \\
\text { reasons }\end{array}$ & 10 & 15 & 2 \\
\hline Psychological & 7 & 11 & 3 \\
\hline Body image issues & 3 & 3 & 0 \\
\hline Fear & 2 & 6 & 1 \\
\hline Interpersonal constraints (total) & 15 & 78 & 22 \\
\hline Parents & 14 & 22 & 11 \\
\hline Friends & 11 & 14 & 5 \\
\hline Fear of criticism/judgment & 8 & 25 & 3 \\
\hline Boyfriends/girlfriends & 2 & 3 & 1 \\
\hline Structural constraints (total) & 15 & 88 & 37 \\
\hline $\begin{array}{l}\text { Risk of harm-external to } \\
\text { activity }\end{array}$ & 13 & 19 & 15 \\
\hline Time & 13 & 19 & 9 \\
\hline $\begin{array}{l}\text { Availability of facilitics/ } \\
\text { equipment }\end{array}$ & 10 & 13 & 2 \\
\hline Cost of participation & 9 & 16 & 7 \\
\hline Location/transportation & 7 & 11 & 4 \\
\hline Weather/season & 3 & 3 & 0 \\
\hline Legality & 1 & 1 & 0 \\
\hline $\begin{array}{l}\text { Sociocultural constraints } \\
\text { (total) }\end{array}$ & 12 & 18 & 1 \\
\hline Gender & 11 & 14 & 0 \\
\hline Religion & 3 & 3 & 0 \\
\hline Age & 1 & 1 & 1 \\
\hline Race & 0 & 0 & 0 \\
\hline $\begin{array}{l}\text { Risk of harm-internal to } \\
\text { activity }\end{array}$ & 13 & 66 & 0 \\
\hline Other constraints & 2 & 2 & 1 \\
\hline
\end{tabular}

Interviewee 1:Some people don't like the rules of the game. Interviewer: Which rules don't they like?

Interviewee 2: Where they actually, like, jump, like, far and then you have to stop. You have to shoot; you can't run with the ball ... Um, some people don't like to wear skirts and vest.

Disinterest was sometimes framed in terms of activities, especially reading and napping, being boring. Adolescents also sometimes 
discussed specific dislikes for profanity, violence, or sexually explicit content, often in the context of their media use activities. When describing what she did not like about watching television, one eighth grade girl said, "The violence, it reflects on our children."

In the face of limited time, the relative strength of preferences for multiple activities sometimes constrained participation in lesspreferred activities; for example, an eighth grade girl noted that "I don't like [netball] because I like soccer playing." Competing preferences were often associated with gender. As one tenth grade girl said in response to a question about why girls are more likely to sing: "Boys like soccer, girls like to sing." In sum, dislike and disinterest encompassed diverse specific constraints, from rules to antisocial activity elements to competing interests.

Moving beyond disinterest, another intrapersonal constraint that participants identified was a lack of skill or ability in activities as varied as sports, shooting pool, video games, singing, dancing, reading, and playing a musical instrument. A tenth grade girl said, "I think the one bad thing about singing is if you don't have [the] voice for singing, then don't try it." A lack of skill was often attributed to girls specifically; this finding is discussed in greater detail in Gleeson (2008).

According to participants, adolescents sometimes lacked the ability to participate in leisure because of their health. In fact, physically disabled was the most frequent response to the question about types of students excluded from activities, as one eighth grade boy indicated: "And some people can't play it because say for instance you have one leg... now you can't go play rugby or tennis or basketball." Other health-related constraints included breathing problems (from asthma or smoking) and being overweight or unfit.

Participants also discussed intrapersonal constraints that were of a psychological nature. These included both personality traits, such as being quiet or shy, as well as constraints related to emotion and cognition, such as a lack of self-confidence. In the words of an eighth grade boy, "I say everyone can do a sport because those that don't want to, they . . . they don't believe in themselves." Issues of body image also emerged during discussions of swimming and reluctance to wear a bathing suit. 
Fear was sometimes mentioned as a leisure constraint. However, fear was mentioned exclusively in relation to girls and reasons for their nonparticipation in sports and other physical activities. This finding is discussed in greater depth in Gleeson (2008).

Interpersonal constraints. As with intrapersonal constraints, interpersonal constraints were mentioned in all 15 focus groups; however, interpersonal constraints were mentioned somewhat less frequently (Table 1). Parents were the most common interpersonal constraint to leisure participation, being mentioned in all but one group. Parental constraints often came in the form of trying to protect children from the dangers in their peer groups and neighborhoods, as indicted by these eighth grade boys:

Interviewer: What might keep you from being able to do the things you want to do?

Interviewee: Your parents say no.

Interviewer: .... Why do you think they might say no?

Interviewee: They think you gonna get hurt... And you gonna do the wrong things when you go there.

Interviewer: Like what?

Interviewee: Like smoke or something like that . . or you'll get in a fight. Parental constraint was sometimes perceived by participants as being overprotective.

In other cases, parental leisure restriction seemed to be driven less by safety concerns and more by morality. One eighth grade boy stated: "Um, not all the children has boyfriends and girlfriends because, um, maybe their parents think that they should wait for the time." In the words of an eighth grade girl, "Watching TV, like, um, sometimes ... your parents [that] is at home doesn't want you to because, like, where it says about the violence... 'you can't watch that, it's gonna influence you." In other instances, participants reported that parents constrained leisure by imposing constraints on time, such as household chores and religious involvement.

Friends and peers also represented interpersonal leisure constraints. This often took the form of friends pressuring participants to abandon a preferred activity and perhaps pressuring them into an alternate activity, as noted by one eighth grade girl: 
Um, say now like you want to go play soccer. Your friends tell you, "No, come, we gonna party, we go do drugs and stuff like that." Then they tell you if you don't do it and then they gonna tease you or you not cool or something like that.

On occasion, the absence of friends with whom to participate also represented a constraint to leisure. Friends and others were sometimes a source of judgment or criticism that might constrain leisure participation. In certain situations, the activity in general was criticized, as indicated by this tenth grade boy:

Sometimes your friends then disagree with what you do ... Someone said, like, um, when you [do] drama, guys think that you a "moffie" (gay) or something like that . . . So then your friends give you that impression that, when you do drama, that you this kind of person. So they stand actually in your way of succeeding in

Participants also discussed how they sometimes received criticism about their individual performance in an activity, as shown by this tenth grade girl:

Say for instance you wanna dance and you can't and there's, like, other children or friends would say, "No, sit down, you can't dance, don't try it." And then it makes you feel bad because they not even saying it, "Okay, we gonna help you dance, get rhythm.” They just say, "Sit. You can't."

Dating partners were mentioned as a leisure constraint in two of the focus groups. A tenth grade boy discussed the ways in which a girlfriend might restrict time use:

"A girl sometimes they don't want you to, like, go to . . y your friends because you spend most of your time with your friends really and they want you to spend time with them." Similarly, a group of tenth grade girls discussed issues of possessiveness and control in dating relationships: "The guy sometime[s] don't trust you, or even the girl don't trust you, so then you can't go even if you want to."

Structural constraints. As with intrapersonal and interpersonal constraints, structural constraints were mentioned in all focus 
groups, with a frequency similar to that of inter- personal constraints (Table 1). One of the most commonly mentioned structural constraints was competing demands on time, such as chores, schoolwork, or sibling care, as discussed by a tenth grade boy:

"After school you playing [table tennis] for a team, you play for the school. But now you have a game the next day, and then, like, you wanna practice and the workload of the teachers is not so agreeable..."

Participants in 13 of the focus groups raised concerns about the possibility of harm in activities that came from sources external to that activity. These statements were often made in response to the specific probe about whether their neighborhood was a safe place for activities. Specific safety threats included gang and drug activity. A frequent complaint was theft on the part of gang members, as exemplified by the following excerpt from a group of tenth grade boys:

"They can rob you ... Take your boots off, soccer boots ... Take your clothes off. What you have they take. Your money . .. Or the equipment and the transportation money that you have."

Participants in 10 of the focus groups discussed leisure constraints related to a lack of facilities or equipment. This included not having a ball for soccer, electricity to play video games, or a television set, as well as having low mobile phone batteries or a flat bicycle tire. Participants also discussed a more general lack of leisure resources in their homes, schools, and communities. For example, a tenth grade girl said that in her community "there's no place where you can play the sports."

Similar to the idea of a lack of facilities, participants in about half of the focus groups mentioned an activity's location, or related transportation issues, as a constraint to participation. As one tenth grade girl stated, "If there is a game shop nearby then you will basically go, but if there isn't one then you won't."

Financial constraints were mentioned in nine focus groups. Sometimes, participants could not afford fees for accessing activities such as soccer clubs, shooting pool, shop- ping, and using the 
Internet. Participants also discussed prohibitive costs for equipment, transportation, or appropriate clothing.

Weather was another structural constraint that participants mentioned. Participants in two focus groups discussed not being able to play cricket or go swimming in the winter or when the weather was not nice. Another group felt that weather had an indirect effect on participation based on its impact on mood. As an eighth grade girl stated, "The sun make you lazy."

Despite the frequent mention of illegal risk behaviors as free-time activities (see Patrick et al., 2010), legality was only mentioned as a leisure constraint in one focus group, with one eighth grade boy stating that drug use might lead to theft.

Sociocultural constraints. Overall, sociocultural constraints were the least frequently mentioned type of constraint, being discussed an average of one time per focus group (see Table 1). Gender was, by far, the most frequently mentioned sociocultural leisure constraint. On most occasions, gender constraints took the form of perceptions that requisite skills or preferences for a specific activity were inherent to one gender only. It was almost always girls who were hindered in their potential participation in "boys' activities":

Interviewer: Okay, what do you think it is about PlayStation that makes boys wanna play?

Interviewee 1: $\quad$ It's exciting... games.

Interviewer: Okay, and so girls don't want things that are exciting and fun and different?

Interviewee 1: They do.

Interviewer: . . . . Okay, what makes them not choose PlayStation? Interviewee 2:There [are] things boys like that girls don't like. Interviewee 1: Like soccer playing on the PlayStation, rugby, car games. Interviewer: .... Why do you think it is that they don't like it?

Interviewee 3: $\quad$ They don't have the skill to play games. Interviewer: And why do you think they don't have the skills? Interviewee 3: They don't try.

Interviewee 2: . . . They [are] not used to the controls. 
Less frequently, gender constraints took the form of overt discrimination, typically with boys telling girls that they could or should not participate in "boys' sports” (see Gleeson, 2008).

Religion was mentioned as a leisure constraint in three focus groups. In two groups, church/mosque attendance and religious studies were mentioned as specific types of time- related constraints. In the other group, an eighth grade boy discussed how fasting for Muslim holy days might constrain sports participation: "They can't play [soccer] in the fast otherwise you get thirsty and you can't eat."

Contrary to our expectations, race was never mentioned as a constraint to leisure participation. Possible explanations for this finding are discussed below.

Other constraints. Participants mentioned several other constraints to leisure partici- pation that did not fit neatly within the four categories discussed above. One such constraint was risk of harm because of activities themselves; it was mentioned an average of five times in each of 13 focus groups. Risk of harm from activities was often discussed in the context of what participants did not like about specific activities. For example, participants discussed the risk of soreness or injury, mostly in physical activities like rugby, soccer, and ice skating. Sunburn and drowning were mentioned as possible risks for swimming. Two groups discussed "sore lips" as something they disliked about playing musical instruments. Participants in several groups also discussed risks associated with people they met on MXit, a mobile phone-based chat program:

Sometimes you meet the wrong people on MXit... That's if you want to meet somebody, sometimes you can meet the wrong person. Like maybe somebody would say, "No, I'm 16. I'm going to meet you tomorrow. Can we hook up?" and stuff like that. And then you come and then you meet a 30-year-old man ... a stalker.

When participants discussed risk behaviors in which they engaged during free time, risk of harm was often mentioned. This included cardiovascular and respiratory problems for smoking, physical injury for fighting, and disease and pregnancy for sex. (See Patrick et al., 2008, for a more complete discussion of adolescents' perceived risks of substance use and sexual behavior.) 
Not having something to wear and "being naughty" were also mentioned as con- straints to leisure participation, but with insufficient detail to classify them under one of the previously mentioned categories of constraints.

\section{Overcoming Leisure Constraints}

Overcoming intrapersonal constraints. Strategies for overcoming intrapersonal con- straints were rarely mentioned, especially considering the comparatively high frequency with which these factors were discussed as leisure constraints (Table 1).

Tenth graders in three focus groups mentioned positive self-talk and self-acceptance as ways of overcoming constraints related to selfconfidence and self-esteem. Participants in two focus groups discussed overcoming health-related constraints, in the form of overweight 
individuals exercising and physically disabled adolescents playing wheelchair basketball. A number of intrapersonal constraints, including body image and the lack of interest and skill, did not have any accompanying strategies for overcoming them.

Overcoming interpersonal constraints. As compared with intrapersonal constraints, participants discussed overcoming interpersonal constraints with much higher frequency (Table 1). Participants in seven focus groups discussed multiple ways for overcoming leisure constraints related to parents, including disobeying parental restrictions and having high self-esteem in order to counter a lack of parental emotional support. Participants also discussed the use of communication strategies, including negotiation and expressing one's preferences, as indicated by this tenth grade girl:

Speaking to your parents and tell them that, um, you can do things, you can help with your siblings and that, but they must also give you time for yourself because you are growing up now and you also want to be out there and see what is happening around you.

These strategies aside, participants in one focus group of tenth grade boys stated that there was no way to overcome parental obstacles:

I don't think it help with the parents because parents always have something to say. Like, I want to go to the games, to pool to shoot [with] people, and then they always, like, say, because we have a drug merchant opposite us, and so they will always, like, have ... something to say. "No, you can't go out, it's late, it's over here and the stuff [is] going on." And so I always [have] an excuse. So I don't think you can come past your parents.... You will just have to listen to what they say.

Participants in five focus groups discussed coping with friends who constrain leisure. This typically involved not listening to friends and either doing an activity on one's own or finding different activity partners. However, a group of tenth grade boys discussed time management as a way of overcoming constraints related to friends and significant others: "I say you must use your time wisely ... Like you spend 30\% time with your girlfriend then the others, your friends and whatever, your ways." 
Members of one focus group with tenth grade girls discussed overcoming fears of criticism and judgment. One girl discussed staying home to avoid criticism whereas another discussed the use of positive self-talk: "If you can just tell yourself that 'I can do it,' then you can do it. Don't listen to other people who are criticizing you."

Overcoming structural constraints. As compared with the other types of constraints, participants were most likely to mention ways of overcoming structural constraints to leisure (Table 1). Participants most frequently discussed overcoming risk of harm from sources external to an activity. An eighth grade girl stated that adolescents could overcome the obstacle of danger in their neighborhoods if they "walk in large groups or have your parents with you sometimes." A group of eighth grade boys discussed the feasibility of alternate activity locations as a way to avoid gang violence: "If you do it in the house ... Or in the yard ... But you can't shoot pool in the yard." Other strategies for dealing with safety concerns included not being out after dark, moving to a different neighborhood, and either standing up to, ignoring, or befriending gangsters and other negative social figures.

Two focus groups explicitly stated that there was no way to get around constraints related to neighborhood safety. In a third focus group, one tenth grade girl discussed the role that individuals and communities play in overcoming crime as a constraint to leisure participation:

It's actually, if you, um, if you stand alone against those gangsters, then it's like they gonna overpower you because they [are] more than what you are. You [are] a person alone.... . If the community is too scared to stand up to them, one person can't just do it alone. I can speak and speak and speak but they won't listen.

Participants in eight focus groups discussed overcoming time constraints. This included waking up earlier or staying up later, doing chores quickly, and "multitasking" (e.g., doing homework during class time, listening to music while washing dishes). Other strategies for dealing with time constraints involved delegation or negotiation, as described by one tenth grade girl: 
can make a deal with a sister or a brother or any family member in the house and then you can do it the next time when it must be done.

Participants in seven focus groups discussed ways to overcome the constraint of activity cost. This typically took the form of working a part-time job, or stealing or borrowing money from others. Four groups of participants discussed overcoming transportation constraints by walking to an activity, taking paid transportation, or finding closer locations for activities. Participants in two groups discussed ways to overcome a lack of equipment and facilities.

Overcoming sociocultural constraints. Participants in only one focus group discussed a strategy for overcoming sociocultural constraints. This came in the form of an eighth grade girl describing how one could circumvent age restrictions at dance clubs by arriving during the under age 18 matinee. No participants discussed overcoming barriers related to gender or religion.

\section{Discussion}

The first aim of this study was to document the types of leisure constraints identified by adolescents in an underresourced area of South Africa. Consistent with previous literature, focus group participants discussed intrapersonal, interpersonal, structural, and sociocultural constraints. Generally, the specific examples of constraints within each type have also been documented in previous studies. These similarities are noteworthy given that most empirical studies of leisure constraints have used U.S. or Canadian samples. Despite differences in culture, geography, and resources, it appears that there may be some degree of universality in the types of activity constraints that adolescents face. This suggests that South African researchers and practitioners could possibly use North American theory and research as a starting point for efforts related to adolescent leisure constraints, while also being open to more nuanced cross-national differences that may exist.

Despite these similarities, it is important to note that no previous studies have documented the diverse range of specific constraints subsumed under dislike or disinterest of activities that our sample reported. Focus group participants expressed dislike not only for 
particular activities in general, but also for a wide range of specific experiences within those activities. Identifying these more specific preference constraints may be a first step in developing recommendations for activity leaders to address them. For example, adapting activity rules or emphasizing rewards that are more intrinsic than winning may boost adolescent interest. However, certain preference-related constraints, such as disliking profanity or violence in media activities, may actually be protective for adolescents and are best left as non-negotiated.

Focus group participants identified one type of constraint that had not been previously documented and did not seem to fit within the existing leisure constraint typology: risk of harm inherent to an activity. Specific risks included sports injuries, drowning, and physical consequences of substance use and sexual behavior, and they seemed to cut across the constraints hierarchy. Risk of harm may relate to certain intrapersonal constraints, impacting preference for an activity, engendering fear of an activity, or reflecting a lack of skill or ability that would allow for safer participation. Risk of harm could also stem from certain structural constraints, such as a lack of proper equipment, facilities, supervision (e.g., lifeguard for swimming), or instruction. Efforts to boost leisure participation and enjoyment should not overlook participants' perceived risk of harm from involvement, which is not neatly classified but may reflect a broad range of underlying issues.

The second aim of this study was to examine the relative frequencies at which the various types of leisure constraints were identified. Consistent with previous research, intrapersonal constraints were the type of constraint most frequently mentioned by participants (Gyurcsik et al., 2006; Raymore et al., 1994). Disinterest was the most frequently mentioned intrapersonal constraint; however, lack of skill or ability was also mentioned in the majority of focus groups, which may suggest the need for training resources and for opportunities to involve individuals of varying abilities in a given activity.

Interpersonal constraints were mentioned about half as often as intrapersonal constraints. Of all interpersonal constraints, parents were mentioned the most often and in the most focus groups. This is consistent with previous research in the United States (Hultsman, 
1993). If one had the goal of reducing this constraint, these findings suggest there may be utility in integrating a parent education component into leisure education efforts. The con- tent might focus on benefits of and resources for adolescent leisure, as well as strategies for negotiating with adolescents about their desired leisure involvement. However, it is also important to acknowledge that parents may be restricting leisure for legitimate reasons that actually enhance the well-being of their children. Focus group participants frequently discussed their neighborhoods as risky settings that included gang violence and drug activity. Therefore, it may be possible to reduce perceived parental constraints indirectly by measures targeted at improving neighborhood safety, as discussed below.

Structural constraints were mentioned at roughly the same frequency as interpersonal constraints. The most common of these constraints was risk of harm external to an activity, which may be due, in part, to aforementioned crime in participants' neighborhoods. The frequency with which this constraint was identified is one of the most notable ways the findings from this study differ from studies of other populations. It suggests a need for providing safe leisure spaces through funding (e.g., for physical barriers and security personnel to keep criminals out) and policy (e.g., to require community policing of leisure spaces and penalties for individuals disrupting those spaces). There is also a need for safe transportation between home and leisure spaces, perhaps in the form of a dedicated activity bus.

Sociocultural constraints were mentioned infrequently. Given the prominence of race as a sociopolitical issue in South Africa, it was surprising that race was never mentioned as a constraint to leisure. However, these counts should not necessarily be accepted as evidence of an absence of sociocultural constraints. Culture may be a driving force behind certain intrapersonal, interpersonal, and structural constraints (Philipp, 1995). For example, whether or not adolescents are aware of it, prejudice and discrimination might be a cause of disinterest or a lack of facilities, racial economic disparities may drive perceived cost constraints, and a lack of socialization in a given activity within one's racial or ethnic group might create constraints in skill or interest. Also, participants in this study lived in communities that were fairly homogenous. To the degree that adolescents' leisure participation is limited to their own communities, 
race may not be a salient constraint.

The third aim of this article was to document the constraints negotiation strategies that adolescents discussed and examine their correspondence to identified constraints. Methods for overcoming intrapersonal constraints, such as modifying aspects of an activity to better suit one's interests or practicing to improve skills, went largely unmentioned. This is consistent with a previous study showing that the modification of preferences was a relatively uncommon strategy for dealing with leisure constraints (Jackson \& Rucks, 1995). Therefore, education about ways to overcome intrapersonal constraints may represent an important topic area for interventions focused on improving leisure experiences.

Participants also discussed few strategies for circumventing sociocultural constraints to leisure. This, coupled with few mentions of sociocultural constraints in general, suggests that adolescents may not have a conscious awareness of this type of constraint to their leisure. There may be value in a leisure curriculum that explicitly discusses the cultural norms and values that shape leisure behavior, as well as potential strategies for dealing with cultural constraints. This is consistent with Samdahl's (2005) concept of negotiated meaning, in which participants must sometimes overcome internalizations of restrictive cultural norms and values.

There may also be a role for policy in addressing sociocultural leisure constraints. Institutions that administer activities for adolescents, such as schools or community centers, might consider writing and implementing nondiscrimination policies that allow for the participation of all interested adolescents, particularly in regard to gender. This type of policy might also help to address other constraints, such as physical disability.

Strategies for negotiating interpersonal and structural constraints were mentioned relatively frequently. This may be because these constraints are more concrete than intrapersonal or sociocultural constraints, making it easier for adolescents to think of ways to overcome them. However, regardless of the reason, these findings suggest that adolescents may already have a normative awareness of ways to overcoming interpersonal and structural constraints; increasing awareness of these strategies may not need to be a goal 
of leisure-focused intervention.

\section{Limitations and Future Directions}

There are several limitations to the current study. The chief of these is that the participants were adolescents from four schools in one specific, under resourced area of Cape Town, South Africa. Researchers and practitioners who are interested in understanding leisure constraints among adolescents in other geographic areas should carefully consider the degree to which these results generalize to their own populations of interest. Also, this is a study of adolescents who are participating in an intervention that is, in part, designed to alter leisure-related attitudes and behavior. Therefore, it is unclear whether the results demonstrated here would apply to adolescents without leisure training.

In addition, this study only included participants who were proficient in English. As mentioned previously, this likely only excluded a minority of students. We also felt that the benefits of including nonEnglish speakers were outweighed by the time and expense that would have been required to train Afrikaans- and Xhosa-speaking focus group facilitators and to translate written transcripts into English. In addition, a multilingual research design would have introduced moderator effects that would be necessarily confounded with language effects. However, we do acknowledge that the use of only English-proficient students potentially limits the generalizability of the findings.

It is important to acknowledge that leisure constraint is a complex construct. For ex- ample, constraints may change over time and multiple constraints might interact (Crawford

\& Godbey, 1987). There is also evidence that factors such as gender, socioeconomic status, and self-esteem moderate perceived leisure constraints (Raymore et al., 1994).

In addition, we need to know more about how leisure constraints and negotiation strategies interact with other facets of the leisure experience to influence not only leisure participation but also developmental outcomes more broadly in this population. For example, a recent U.S. study of outdoor recreation suggests that 
motivation and self-efficacy are important factors in the leisure constraints-negotiation-participation process (White, 2008). This suggests the need for multivariate, longitudinal, and person-centered research designs and analyses. We believe that the current study provides a foundation for this type of work by delineating the types of leisure constraints that are relevant for this particular population.

\section{References}

Allison, K. R., Dwyer, J. J. M., Goldenberg, E., Fein, A., Yoshida, K. K., \& Boutilier, M. (2005). Male adolescents' reasons for participating in physical activity, barriers to participation, and suggestions for increasing participation. Adolescence, 4O, 155-170.

Allison, K. R., Dwyer, J. J. M., \& Makin, S. (1999). Perceived barriers to physical activity among high school students. Preventive Medicine, 28, 608-615.

Bartko, W. T., \& Eccles, J. S. (2003). Adolescent participation in structured and unstructured activities: A person-oriented analysis. Journal of Youth and Adolescence, 32, 233-241.

Bronfenbrenner, U. (1977). Toward an experimental ecology of human development. American Psychologist, 32, 513-531.

Caldwell, L. L., \& Baldwin, C. K. (2005). A developmental approach to understanding constraints to leisure. In E. L. Jackson (Ed.), Constraints to leisure (pp. 75-88). State College, PA: Venture Publishing.

Caldwell, L. L., Smith, E. A., Wegner, L., Vergnani, T., Mpofu, E., Flisher, A. J., \& Mathews, C. (2004). HealthWise South Africa: Development of a life skills curriculum for young adults. World Leisure, 3, 4-17

Chick, G., \& Dong, E. (2003). Possibility of refining the Hierarchical Model of Leisure Constraints through cross-cultural research. Paper presented at the Northeastern Recreation Research Sym- posium, Lake George, NY. 
Crawford, D. W., \& Godbey, G. C. (1987). Reconceptualizing barriers to family leisure. Leisure Sciences, 9, 119-127.

Creswell, J. W., \& Miller, D. L. (2000). Determining validity in qualitative inquiry. Theory into Practice, 39, 124-130

Creswell, J. W., \& Plano Clark, V. L. (2007). Designing and conducting mixed methods research.

Thousand Oaks, CA: Sage.

Dworkin, J. B., Larson, R., \& Hansen, D. (2003). Adolescents' accounts of growth experiences in youth activities. Journal of Youth and Adolescence, 32, 17-26.

Eccles, J. S., Barber, B. L., Stone, M., \& Hunt, J. (2003). Extracurricular activities and adolescent development. Journal of Social Issues, 59, 865-889.

Ellison, G. T. H., de Wet, T., IJsselmuiden, C. B., \& Richter, L. M. (1996). Desegregating health statistics and health research in South Africa. South African Medical Journal, 86, 1257-1262.

Fleming, S. (1993). Schooling, sport and ethnicity: A case study. Sociology Review, 3, 29-33.

Gleeson, S. L. (2008). Gender differences in leisure motivation, participation, and constraints for South African adolescents. Retrieved from http://etda.libraries.psu.edu/theses/approved/ orldWideFiles/ETD-2664/Thesis Final.pdf

Gordon-Larsen, P., Griffiths, P., Bentley, M. E., Ward, D. S., Kelsey, K., Shields, K., \& Ammerman, A. (2004). Barriers to physical activity: Qualitative data on caregiver-daughter perceptions and practices. American Journal of Preventive Medicine, 27, 218-223.

Gyurcsik, N. C., Spink, K. S., Bray, S. R., Chad, K., \& Kwan, M. (2006). An ecologically based examination of barriers to physical activity in students from grade seven through first-year university. Journal of Adolescent Health, 38, 704-711.

Hansen, D. M., Larson, R. W., \& Dworkin, J. B. (2003). What 
adolescents learn in organized youth activities: A survey of selfreported developmental experiences. Journal of Research on Adolescence, 13, 25-55.

Hubbard, J., \& Mannell, R. C. (2001). Testing competing models of the leisure constraint negotiation process in a corporate employee recreation setting. Leisure Sciences, 23, 145-163.

Hultsman, W. Z. (1992). Constraints to activity participation in early adolescence. Journal of Early Adolescence, 12, 280-299.

Hultsman, W. Z. (1993). The influence of others as a barrier to recreation participation among early adolescents. Journal of Leisure Research, $25,150-164$.

Iso-Ahola, S. E. (1980). The social psychology of leisure and recreation. Dubuque, IA: William C. Brown Co. Jackson, E. L., Crawford, D. W., \& Godbey, G. (1993). Negotiation of leisure constraints. Leisure Sciences, 15, 1-11.

Jackson, E. L., \& Rucks, V. C. (1995). Negotiation of leisure constraints by junior-high and high- school students: An exploratory study. Journal of Leisure Research, 27, 85-105.

James, K. (2000). "You can feel them looking at you": The experiences of adolescent girls at swimming pools. Journal of Leisure Research, $32,262-280$.

Kelly, J. R. (1987). Freedom to be: A new sociology of leisure. New York, NY: Macmillan.

Kleiber, D. A. (1999). Leisure experiences and human development: A dialectical interpretation. New York, NY: Basic Books.

Kleiber, D. A., Larson, R., \& Csikszentmihalyi, M. (1986). The experience of leisure in adolescence. Journal of Leisure Research, 18, 169-176.

Larson, R. W., \& Verma, S. (1999). How children and adolescents spend time across the world: Work, play, and developmental opportunities. Psychological Bulletin, 125, 701-736. 
Liechty, T., Freeman, P. A., \& Zabriskie, R. B. (2006). Body image and beliefs about appearance: Constraints on the leisure of collegeage and middle-age women. Leisure Sciences, 28, 311-320.

Palen, L., Caldwell, L. L., Smith, E. A., Gleeson, S. L., \& Patrick, M. E. (2008). A mixed-method analysis of free time involvement and motivation among youth in Cape Town, South Africa. Manuscript in progress.

Patrick, M. E., Palen, L., Caldwell, L. L., Gleeson, S. L., Smith, E. A., \& Wegner, L. (2010). A qualitative assessment of South African adolescents' motivations for and against substance use and sexual behavior. Journal of Research on Adolescence, 2O, 456-481.

Pelak, C. F. (2005). Negotiating gender/race/class constraints in the new South Africa. International Review for the Sociology of Sport, 4O, 53-70.

Philipp, S. F. (1995). Race and leisure constraints. Leisure Sciences, 17, 109-120.

Raymore, L. A., Godbey, G. C., \& Crawford, D. W. (1994). Self-esteem, gender, and socioeconomic status: Their relation to perceptions of constraint on leisure among adolescents. Journal of Leisure Research, 26, 99-118.

Samdahl, D. M. (2005). Making room for "silly" debate: Critical reflections of leisure constraints research. In E. L. Jackson (Ed.), Constraints to leisure (pp. 337-349). State College, PA: Venture.

Samdahl, D. M., \& Jekubovich, N. J. (1997). A critique of leisure constraints: Comparative analyses and understandings. Journal of Leisure Research, 29, 430-452.

Scott, D. (2005). The relevance of constraints research to leisure service delivery. In E. L. Jackson (Ed.), Constraints to leisure (pp. 279-293). State College, PA: Venture Publishing.

Searle, M. S., \& Jackson, E. L. (1985). Recreation nonparticipation and barriers to participation: Con- siderations for the management of recreation delivery systems. Journal of Park and Recreation Administration, 3, 23-36. 
Silbereisen, R. K. (2003). Contextual constraints on adolescents' leisure. New Directions for Child and Adolescent Development, 99, 95-101.

Silverman, D. (2005). Doing qualitative research: A practical handbook (2nd ed.). London, UK: Sage.

Statistics South Africa. (2007). Labor force survey: March 2007. Retrieved from http://www.statssa. gov.za/publications/Po210/Po210March2007.pdf

Stewart, D. W., Shamdasani, P. N., \& Rook, D. W. (2007). Focus groups: Theory and practice. Thousand Oaks, CA: Sage.

Stodolska, M., \& Livengood, J. S. (2006). The influence of religion on the leisure behavior of immigrant Muslims in the United States. Journal of Leisure Research, 38, 293-320.

United Nations Development Programme. (2000). South Africa: Transformations for human development. Retrieved from http://hdr.undp.org/en/reports/nationalreports/africa/southafrica/ south africa 2000 en.pdf

United Nations Development Programme. (2006). Human development report 2006. Retrieved from http://hdr.undp.org/en/media/HDRo6complete.pdf

Verma, S., \& Sharma, D. (2003). Cultural continuity amid social change: Adolescents' use of free time in India. New Directions for Child and Adolescent Development, 99, 37-51.

White, D. D. (2008). A structural model of leisure constraints negotiation in outdoor recreation. Leisure Sciences, 30, 342-359. 